http://jmscr.igmpublication.org/home/ ISSN (e)-2347-176x ISSN (p) 2455-0450 crossref DOI: https://dx.doi.org/10.18535/jmscr/v9i6.44

\title{
Inhalation of Vapor with Medication (Diclofenac Sodium, Menthol, Methyl Salicylate and N-Acetyl Cysteine) Reduces Oxygen Need and Hospital Stay in COVID-19 Patients - A Case Control Study
}

\author{
Authors \\ HN Sarker ${ }^{1}$, Masum Ahmed ${ }^{2}$, Linkon Dutta ${ }^{3}$ \\ ${ }^{1}$ Professor (Ex), Medicine, Sher-E-Bangla Medical College, Barishal, Bangladesh \\ ${ }^{2}$ Assistant professor, Respiratory Medicine, Sher-E-Bangla Medical College, Barishal, Bangladesh \\ ${ }^{3}$ Senior stuff nurse, Sher-E-Bangla Medical College Hospital, Barishal, Bangladesh \\ *Corresponding Author \\ Prof. H.N. Sarker
}

\begin{abstract}
Background: In the midst of the devastating COVID pandemic where there is no specific and effective treatment, traditional therapy may help to ease the patient's suffering. Inhalation of vapor (VP) is an essential home remedy for stuffy, running nose in common cold, influenza and sinusitis. Steam inhalation is helpful in destroying the capsid of the SARS-CoV-2 envelope and preventing infection. Vapor with diclofenac sodium, menthol, methyl salicylate and $N$-acetyl cysteine may augment this effect.

Objective: To evaluate the effect of inhalation of vapor with medication and to compare with inhalation of vapor without medication.

Methods and Materials: A case control study taken place in Corona unit, Sher-E-Bangla Medical College Hospital, Barishal. 43 patients with mild to moderate COVID-19 were participated in this study. All are RT-PCR positive cases. Among them 16 patients were in control group and 27 in study group. In study group they were given vapor with Diclofenac Sodium, Menthol, Methyl Salicylate and N-Acetyl Cysteine and control group they were given normal steam/aquatic vapor two times in a day.

Results: This study determined that after regular inhalation of vapor with above medication, oxygen saturation level increased in the study group $384.61 \%$ in the morning and $515.79 \%$ at night comparing the control group. Furthermore, patients of study group need to stay nearly 1 day less in hospital in comparison to control group.

Conclusion: Regular use of vapor with medication reduces oxygen need and hospital stay in COVID-19 patients compared to only steam vapor inhalation.

Keywords: Vapor, RT-PCR, oxygen saturation.
\end{abstract}

\section{Introduction}

The world is facing the second wave of Coronavirus Disease 2019 (COVID-19) pandemic which is the most troublesome challenge to public health. COVID- 19 caused by severe acute respiratory syndrome coronavirus-2 (SARS CoV2) started in Hubei Province, People's Republic of China in December $2019^{[1]}$. The virus has since spread globally rapidly and World Health Organization (WHO) declared COVID- 19 
pandemic on 11th March 2020. The second wave is running and nobody knows where we are in the course of this disease. It becomes a significant challenge for the public health, science, and medical sectors ${ }^{[2]}$.

SARS CoV-2 spreads by droplets from coughing, sneezing, talking and sighing. At present, it is fully recognised that the virus can spread by airborne $^{[3-5]}$. Although much has been discovered regarding the transmission and clinical feature, less is known about the pathophysiology of COVID-19.COVID-19 is primarily the disease of respiratory tract, at least initially. Disease pathophysiology of COVID-19 can be divided into three phases that correspond to different clinical stages of the disease ${ }^{[6]}$.Stage 1: Asymptomatic state (initial 1-2 days of infection) - the inhaled virus SARS-CoV-2 likely binds to epithelial cells in the nasal cavity through ACE2 receptors and starts replicating ${ }^{[7}{ }^{8]}$. Stage 2: Invasion and infection of the upper respiratory tract (next few days) - the virus propagates and migrates down the respiratory tract along the conducting airways. Due to the involvement of the upper airways, the disease manifests with symptoms of fever, fatigue, myalgia, runny nose, sneezing, cough, sore throator digestive symptoms (nausea, vomiting, abdominal pain, and diarrhea).Stage 3: Hypoxia, ground glass infiltrates, and progression to ARDS Unfortunately, about $20 \%$ of the infected patients will progress to stage 3 disease and will develop pulmonary infiltrates and some of these will develop very severe disease (ARDS).

Clinical spectrum of COVID-19 disease is shown in Table 1.

\begin{tabular}{|l|ll|}
\hline \multicolumn{2}{|l|}{ Table 1 Clinical spectrum of COVID-19 disease ${ }^{[910]}$} \\
\hline Severity of disease & Presentation \\
\hline Asymptomatic & $\bullet$ & No clinical symptoms \\
& $\bullet$ & Positive nasal swab test \\
& $\bullet$ & Normal chest X-ray \\
\hline Mild illness & $\bullet$ & Fever, sore throat, dry cough, malaise and body aches or \\
& $\bullet$ & Nausea, vomiting, abdominal pain, loose stools
\end{tabular}

About $80 \%$ of the infected patients have mild disease and mostly restricted to the upper and conducting airways. These individuals may be monitored at home with conservative symptomatic therapy. Around $15 \%$ patients will have moderate disease and only 5\% develop severe and critical illness.

Inhalation of vapor (VP) is an essential home remedy for stuffy, running nose in common cold, influenza and sinusitis. The biggest advantage of breathing in wet, warm steam is that it can help relieve nasal congestion and swelling of blood vessels. Moisture can also help to loose and thin tenacious mucus in sinuses and airways, allowing them to empty more quickly. This allows the breathing to return to normal, if only for a brief time. Menthol is a substance which has a cooling and anesthetic effect. This also decreases the cough reflex and can soothe the dry throat.

For the casual viewer, steam inhalation is one of the most commonly used home remedies for soothing and opening the nasal passages and relieving the effects of a cold or sinus infection. According to the researchers, steam inhalation cycles are helpful in destroying the capsid of the SARS-CoV-2 envelope and preventing infection. 
According to them, the European Pharmacopoeia VI edition has prescribed steam inhalations as a treatment for respiratory disorders ${ }^{[11]}$.

During last year when I and my other 4 family members had been suffering from COVID-19, we inhaled vapor to ease our dry cough. Initially, it gave temporary relief. For better relief I looked for menthol, but I got a gel that contained menthol in addition to methyl salicylate and diclofenac sodium and a nabule of $600 \mathrm{mg}$ of $\mathrm{N}$-acetyl cysteine near my hand. I mixed these two and put it in water in an electric tea-pot. We inhaled that medicated vapor 2-3 times daily during illness and gave better result to relieve cough, easy expectoration of sputum and an astonishing effect of improving oxygen saturation.

In fact, till now there is no specific and effective treatment for COVID-19. Where there is no specific and effective treatment, people and also we, the physicians look for the traditional remedy. Hypoxia is an integral and dangerous feature of severe and critical stage of COVID-19 and maintenance of oxygen saturation is the key to management.

The above observation lead me to conduct this study. In this study, we have tried to determine the effects of inhalation of vapor with medication and to compare with only vapor inhalation. As a consequence, we have taken two groups of population - one study group inhaling vapor with medication and another control group inhaling only vapor.

\section{Method and Materials}

Methods: Case control study.

Population: Adult patients with RT-PCR +ve mild to moderate COVID 19. Severe and critical disease patients had been excluded from the study. Duration: One month

Study Place: Corona unit, Sher-E-Bangla Medical College Hospital, Barishal.

Sample Size: Total 43 patients (N). Among them study group (SG) had 27 respondents and control group (CG) had 16 respondents.
Materials: Suitable vapor producing electric teapot, medicine, pulse oximeter and a structured questionnaire.

Study Group: This group inhaled vapor containing Menthol $0.02 \%$, Methyl salicylate $0.05 \%, \mathrm{~N}-$ Acetyl cysteine $1.2 \mathrm{gm} \%$, and Diclofenac sodium $1 \mathrm{gm} \%$ twice daily in addition to conventional treatment. That is, 100 gram of emulsion contain diclofenac sodium 1 gram, $\mathrm{N}$ acetyl cysteine $1.2 \mathrm{gm}$, menthol $20 \mathrm{mg}$, and methyl salicylic acid $50 \mathrm{mg}$. These drugs have no systemic and local side effects in these small doses, though it may cause slight eye irritation.

Control group: This group inhaled plain aquatic vapor in addition to conventional treatment.

Data Collection Tools: Data has been collected for over a month from the study unit. The whole questionnaire has been administered by the researcher along with a research assistant. The researcher provided training and advocate the assistants for data collection including both subjective feelings (cough, chest pain, breathlessness) 10 minutes after inhalation and objective findings (pulse, respiratory rate and $\mathrm{SpO}_{2}$ ) before and 10 minutes after inhalation and to see the accuracy of collected data. An excel file was prepared for daily data input.

Data Analysis: For data input, SPSS and Microsoft Excel software has been used. Moreover, for data analysis, SPSS version 23 has been used as principal software.

Data Quality Management: Data quality management was performed based on data integrity, completeness, validity, uniqueness, accuracy and consistency. Data quality management has been done by randomly checking data from the questionnaire and find out those errors like incomplete, invalid and irrelevant data from the data set. Data quality management team has been corrected those incomplete data as required.

\section{Results}

In this study 43 respondents participated and information was collect according to protocol. The 
data were collected by the researchers and data were numerically coded and entered into using SPSS 23 version. This has been presented graphically and thematically, and discussed based on the theme developed from the collected data.

Table-2: Distribution of age among study group and control group ( $N=43 ; S G=27, C G=16$ )

\begin{tabular}{|l|c|c|}
\hline \multirow{2}{*}{ Age Range } & Study Group & Control Group \\
\cline { 2 - 3 } & $\mathrm{N}(\%)$ & $\mathrm{N}(\%)$ \\
\hline 20-30 years & $3(11.1 \%)$ & $0(0.0 \%)$ \\
\hline 31-41 years & $0(0.0 \%)$ & $2(12.5 \%)$ \\
\hline 42-52 years & $10(37.0 \%)$ & $5(31.3 \%)$ \\
\hline 53-63 years & $10(37.0 \%)$ & $4(25.0 \%)$ \\
\hline 64-74 years & $3(11.1 \%)$ & $3(18.8 \%)$ \\
\hline$>75$ years & $1(3.7 \%)$ & $2(12.5 \%)$ \\
\hline Total & $27(100.0 \%)$ & $16(100 \%)$ \\
\hline
\end{tabular}

Table 2 showed that age of maximum patients are between $42-52$ years in both study group (37.0\%) and control group $(31.3 \%)$.

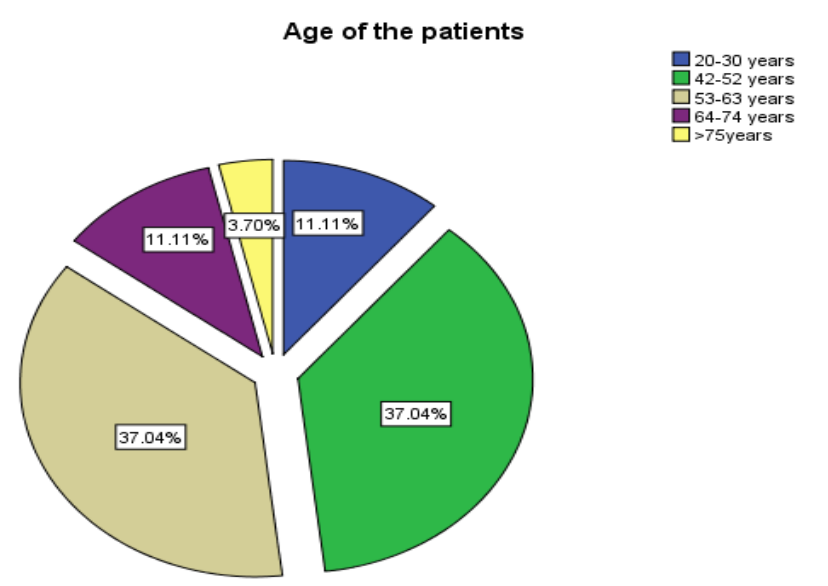

Figure-1: Pie chart of age distribution of the patients.

Table-3: Distribution of gender among study group and control group ( $N=43 ; S G=27, C G=16)$

\begin{tabular}{|l|c|c|}
\hline \multirow{2}{*}{ Sex } & Study Group & Control Group \\
\cline { 2 - 3 } & $\mathrm{N}(\%)$ & $\mathrm{N}(\%)$ \\
\hline Male & $18(66.7 \%)$ & $8(50.0 \%)$ \\
\hline Female & $9(33.3 \%)$ & $8(50.0 \%)$ \\
\hline
\end{tabular}

Table 3 showed that in study group most of the patients were male $(66.7 \%)$ and in control group, male and females were equal in number $(50 \%)$.

Table-4: Comparative table of average hospital stay between study group and control group ( $N=43$; $S G=27$, $C G=16)$

\begin{tabular}{|l|c|c|c|}
\hline Average & Study group & Control Group & Difference of Hospital Stay in respect to control group \\
\cline { 2 - 4 } Hospital Stay & 7.41 days & 8.25 days & $0.84 \cong 1$ day less \\
\hline
\end{tabular}

Above demonstrated table 4 showed that average hospital stay of study group and control group. Statistical analysis reported that those people who take vapor with medication (diclofenac sodium, menthol, methyl salicylate and $\mathrm{N}$-acetyl cysteine) had to stayin hospital nearly one day less than control group. 


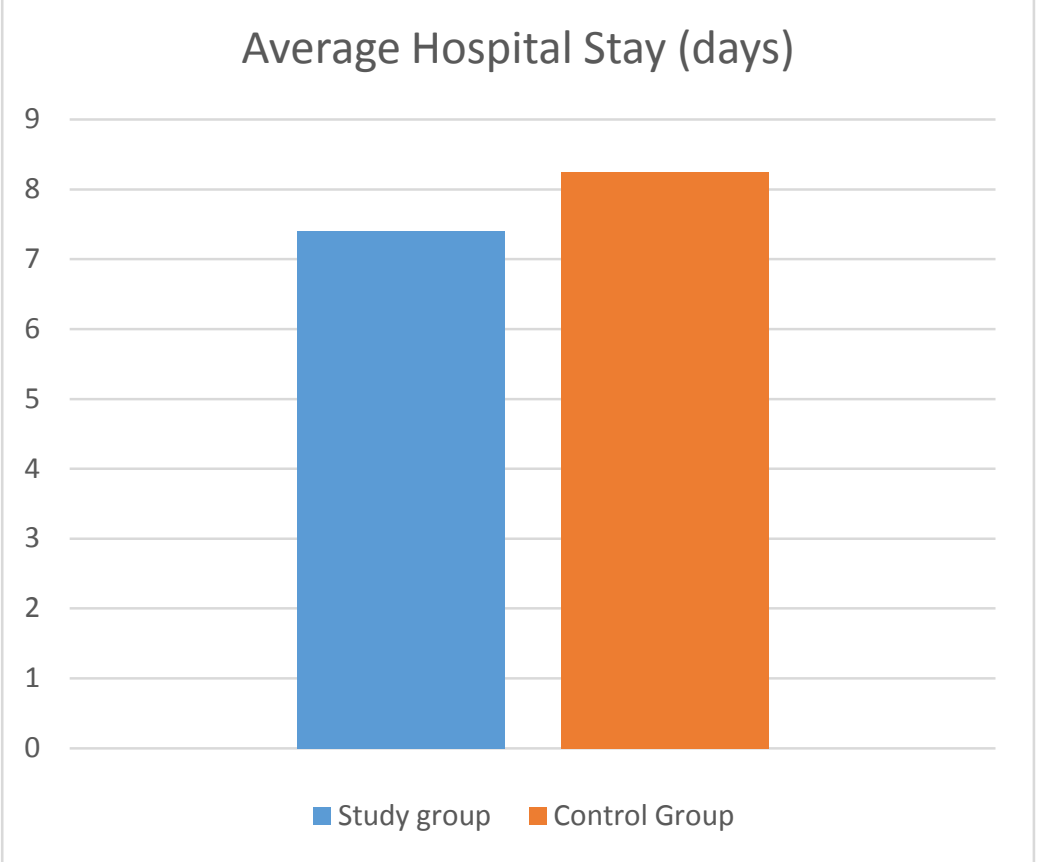

Figure-2: Bar chart of duration of hospital stay.

Figure-2 shows that average hospital stay of study group is 1 day less than control group.

Table-5: Change of oxygen saturation in both study group and control group.

\begin{tabular}{|c|c|c|c|c|c|c|}
\hline Description & $\begin{array}{l}\text { Study } \\
\text { Group } \\
\text { Level of } \\
\text { oxygen }\end{array}$ & $\begin{array}{l}\text { Oxygen } \\
\text { saturation } \\
\text { changed in } \\
\text { Study group }\end{array}$ & $\begin{array}{c}\text { Control } \\
\text { GroupLevel of } \\
\text { oxygen }\end{array}$ & $\begin{array}{l}\text { Oxygen } \\
\text { saturation } \\
\text { changed in } \\
\text { control } \\
\text { group }\end{array}$ & $\begin{array}{l}\text { Difference of } \\
\text { oxygen } \\
\text { saturation } \\
\text { changed with } \\
\text { respect to } \\
\text { control group }\end{array}$ & Significance \\
\hline $\begin{array}{l}\text { Average } \mathrm{SPO}_{2}{ }^{-} \\
\text {before VP in } 8 \mathrm{AM}\end{array}$ & 95.47 & \multirow[b]{2}{*}{1} & 95.59 & \multirow[b]{2}{*}{0.26} & \multirow[b]{2}{*}{$384.61 \% \uparrow$} & \multirow[b]{2}{*}{$0.000 *$} \\
\hline $\begin{array}{l}\text { Average } \mathrm{SPO}_{2}-10 \\
\text { minute after VP from } \\
8 \mathrm{AM}\end{array}$ & 96.47 & & 95.85 & & & \\
\hline $\begin{array}{l}\text { Average } \mathrm{SPO}_{2}{ }^{-} \\
\text {before VP in } 8 \mathrm{PM}\end{array}$ & 95.74 & \multirow[b]{2}{*}{0.98} & 95.70 & \multirow[b]{2}{*}{0.19} & \multirow[b]{2}{*}{$515.79 \% \uparrow$} & \multirow[b]{2}{*}{$0.000^{*}$} \\
\hline $\begin{array}{l}\text { Average } \mathrm{SPO}_{2}-10 \\
\text { minute after } \mathrm{VP} \text { from } \\
8 \mathrm{PM}\end{array}$ & 96.72 & & 95.89 & & & \\
\hline Total Average & 96.1 & & 95.75 & & & \\
\hline
\end{tabular}

Table 5 shows that after taking vapor with medication helps to increaseSpO $3384.61 \%$ and $515.79 \%$ respectively in morning and evening respectively in comparison to control group. 


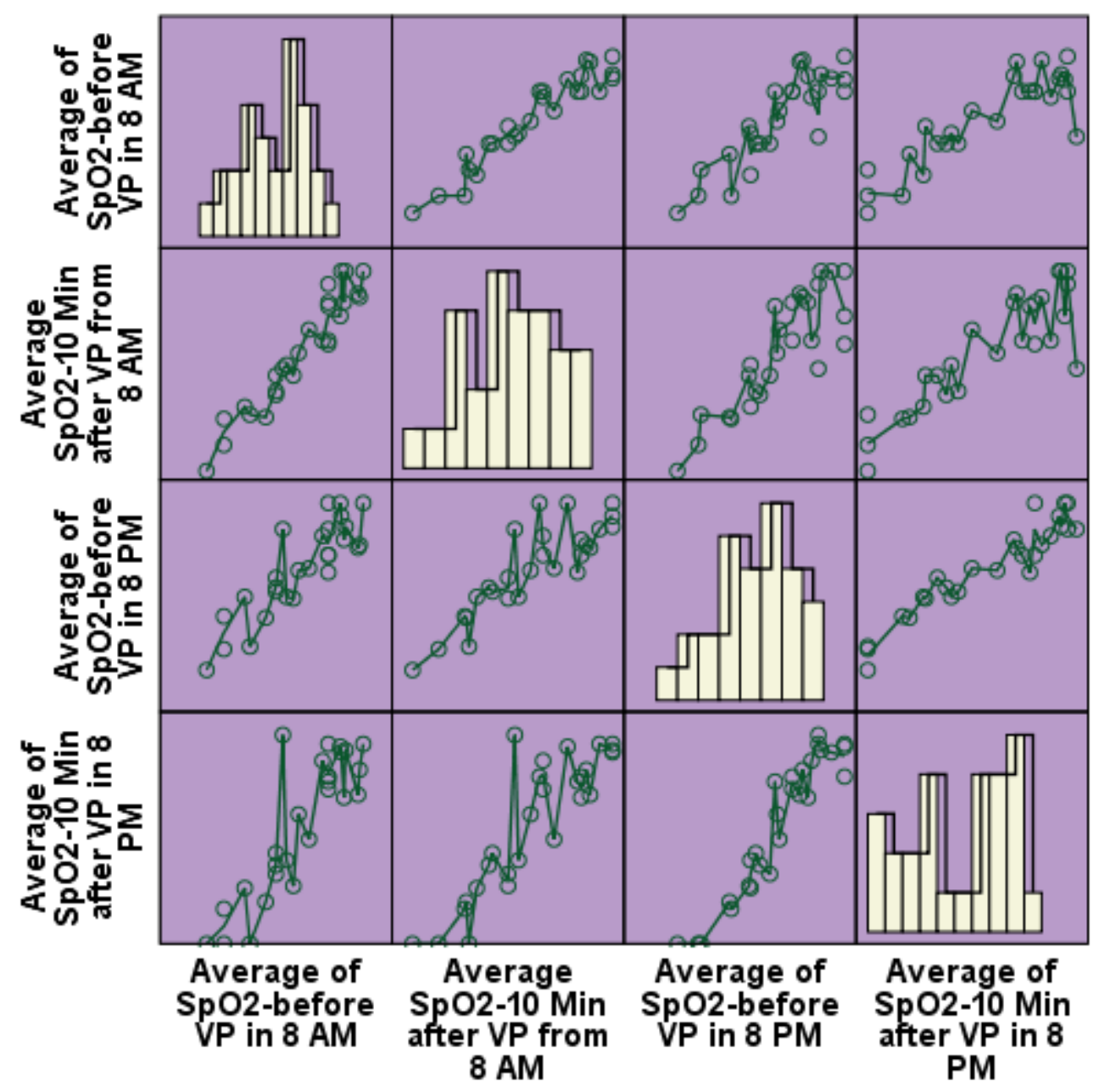

Figure-3: Correlation matrix of study group.

Figure- 3 shows that vaporization (with diclofenac sodium, menthol, methyl salicylate and n-acetyl cysteine) and oxygen saturation level are significantly associated.

Table-6: Table of paired sample T test among Study group.

\begin{tabular}{|c|c|c|c|c|c|c|c|c|c|}
\hline \multicolumn{10}{|c|}{ Paired Samples Test } \\
\hline & & \multicolumn{5}{|c|}{ Paired Differences } & \multirow[t]{3}{*}{$\mathrm{t}$} & \multirow[t]{3}{*}{ df } & \multirow{3}{*}{$\begin{array}{l}\text { Sig. (2- } \\
\text { tailed) }\end{array}$} \\
\hline & & \multirow[t]{2}{*}{ Mean } & \multirow[t]{2}{*}{$\begin{array}{c}\text { Std. } \\
\text { Deviation }\end{array}$} & \multirow[t]{2}{*}{$\begin{array}{l}\text { Std. Error } \\
\text { Mean }\end{array}$} & \multicolumn{2}{|c|}{$\begin{array}{c}95 \% \text { Confidence Interval } \\
\text { of the Difference }\end{array}$} & & & \\
\hline & & & & & Lower & Upper & & & \\
\hline $\begin{array}{l}\text { Pair } \\
1\end{array}$ & $\begin{array}{l}\text { Average SpO2-10 } \\
\text { Min after VP from } 8 \\
\text { AM - Average of } \\
\text { SpO2-before VP in } 8 \\
\text { AM }\end{array}$ & .99741 & .36719 & .07067 & .85215 & 1.14266 & 14.114 & 26 & .000 \\
\hline $\begin{array}{l}\text { Pair } \\
2\end{array}$ & $\begin{array}{l}\text { Average of } \mathrm{SpO} 2-10 \\
\text { Min after VP in } 8 \mathrm{PM} \\
\text { - Average of } \mathrm{SpO} 2- \\
\text { before VP in } 8 \mathrm{PM}\end{array}$ & .97778 & .32304 & .06217 & .84999 & 1.10557 & 15.728 & 26 & .000 \\
\hline
\end{tabular}

Table 6 reports the mean and standard deviation of the difference scores for each pair of variables Pair-1 (Mean .99741) and Pair-2 (Mean .97778). The mean is the difference between the sample means. The mean difference between Pair
1(Average SpO2-10 Min after VP from 8 AM Average of SpO2-before VP in $8 \mathrm{AM}$ ) and Pair 2 (Average of SpO2-10 Min after VP in $8 \mathrm{PM}$ Average of SpO2-before VP in $8 \mathrm{PM}$ ) both are statistically significant at $\alpha=0.05$. This is because 
'Sig. (2-tailed)' or $\mathrm{p}>0.05$. In this study found that $95 \%$ confident that correlation of Average SpO2-10 Min after VP from 8 AM - Average of SpO2-before VP in $8 \mathrm{AM}$ between 0.85215 to 1.14266 and Average of SpO2-10 Min after VP in $8 \mathrm{PM}$ - Average of SpO2-before VP in $8 \mathrm{PM}$ among 84999 to 1.10557 in the control group.

\section{Discussion:}

Steam inhalation can destroy the capsid of the SARS-CoV-2 envelope and is helpful in preventing COVID-19 infection ${ }^{[11]}$. It also relieves congestion and loosen thick tenacious mucus making it easy to clear. Menthol decreases the cough reflex, can soothe the dry throat and helps to clear the airways. Methyl salicylate and diclofenac sodium are non-steroidal antiinflammatory drugs, which may reduce pain and inflammation in the respiratory tract that is an important component of pathophysiology of COVID-19. N-acetyl cysteine is an established mucolytic agent which is usually used as an effervescent tablet or solution for nabulisation. Nabulisation is an aerosol generating procedure which is relatively contraindicated in COVID-19 patients.

Vapor inhalation is an essential home remedy in the initial stage of COVID 19 infection. Vapor with these medications loosen the thick mucus, helps to clear it easily, ease the breathing and speeds up removal of virus. In this study, we have tried to evaluate the effect of vapor with medications on mild to moderate COVID-19 patients and to compare with only vapor inhalation.

In this study, 43 patients were randomly selected. All these patients are RT-PCR positive mild to moderate COVID patients. They were divided into two groups -the study group and the control group. In table-2 and Figure-1, the age distribution of the patients among the two groups is shown. The maximum patients were between the age of 42-52 years in both study groups $(37.0 \%)$ and the control group (31.3\%).Table-3 shows that among all the respondents males were high in percentage in study group $(66.7 \%)$.

In this study where patients of study group was given vapor with diclofenac sodium, menthol, methyl salicylate and $\mathrm{N}$-acetyl cysteine at $8 \mathrm{AM}$ and 8PM. On the other hand control group was given normal aquatic vapor at the same time. Maximum patients $(87.50 \%)$ need to stay 5-10 days and $12.50 \%$ patients $1-5$ days in the hospital. It was observed that patient of study group stayed in the hospital in an average 7.41 days. Besides, patients of control group were 8.25 days in hospital (Table-4). It shows that patients of study group stayed nearly 1 day less in hospital in comparison to control group (Fig-2). So it is easily understandable that regularvapor inhalation with medication helps to reduce hospital stay.

Pulse oximeter was used to measure oxygen level $\left(\mathrm{SpO}_{2}\right)$ of the participants. In the study group patients had average $\mathrm{SpO}_{2} 95.47$ before VP at 8 AM and96.47, 10 minute after VP at $8 \mathrm{AM}$, and average $\mathrm{SpO}_{2}$ were 95.74before $\mathrm{VP}$ at $8 \mathrm{PM}$ and 96.72,10 minute after VP at 8 PM. Oxygen saturation level was increased by 1 in the morning and 0.98 at night (Table-5).

On the other hand, in the control group, the average $\mathrm{SpO}_{2}$ was 95.59 before VP at $8 \mathrm{AM}$ and 95.85, 10 minute after $\mathrm{VP}$ at $8 \mathrm{AM}$, and the average $\mathrm{SpO}_{2}$ was 95.70 before VP at $8 \mathrm{PM}$ and 95.89,10 minutes after $\mathrm{VP}$ at $8 \mathrm{PM}$. Oxygen saturation level is increased by 0.26 in the morning and 0.19 at night (Table-5). It is clearly determined that oxygen saturation level is increased in the study group $384.61 \%$ in the morning and $515.79 \%$ at night comparing the control group after inhalation of vapor with medication. It is statistically significant at $\alpha=0.005$.

The mean and standard deviation of the difference scores for each pair of variables Pair-1 (Mean .99741) and Pair-2 (Mean .97778). The mean is the difference between the sample means. The mean difference between Pair 1(Average $\mathrm{SpO}_{2}-10$ Min after VP from $8 \mathrm{AM}$ - Average of $\mathrm{SpO}_{2-}$ before VP in $8 \mathrm{AM}$ ) and Pair 2 (Average of $\mathrm{SpO}_{2-}$ 
10 Min after VP in $8 \mathrm{PM}$ - Average of $\mathrm{SpO}_{2}$ before $\mathrm{VP}$ in $8 \mathrm{PM}$ ) both are statistically significant at $\alpha=0.05$. This is because 'Sig. (2tailed)' or $\mathrm{p}>0.05$. In this study found that $95 \%$ confident that correlation of Average $\mathrm{SpO}_{2}-10$ Min after VP from $8 \mathrm{AM}$ - Average of $\mathrm{SpO}_{2}$ before VP in 8 AM between 0.85215 to 1.14266 and Average of $\mathrm{SpO}_{2}-10 \mathrm{Min}$ after VP in $8 \mathrm{PM}$ Average of $\mathrm{SpO} 2$-before $\mathrm{VP}$ in $8 \mathrm{PM}$ among .84999 to 1.10557 in the control group.

From the above discussion we can come to the point that vapor with diclofenac sodium, menthol, methyl salicylate and $\mathrm{N}$-acetyl cysteine gives better result in COVID 19 patients in both reduction of oxygen needs and reduction of hospital stay compared with normal vapor inhalation.

\section{Conclusion}

In this situation of devastating COVID pandemic where there is no specific and effective treatment, traditional therapy may help to ease the patient's suffering. Regular vapor inhalation can prevent the deadly infection COVID 19 and vapor inhalation with above medication can help to reduce the symptoms, restore the breathing to normal, though only for a brief period, and reduce oxygen need and hospital stay.

This was a small study. So large studies are needed to verify the result.

\section{References}

1. WHO | Pneumonia of unknown cause China. 2020 [cited 2021 Apr 24]; Available from: https://www.who.int/csr/don/05january-2020-pneumonia-of-unkown-causechina/en/de

2. Wit E, van Doremalen N, Falzarano D, Munster VJ. SARS and MERS: recent insights into emerging coronaviruses. Nat Rev Microbiol. 2016;14(8):523-34.

3. Asadi S, Wexler AS, Cappa CD, Barreda S, Bouvier NM, Ristenpart WD. Aerosol emission and superemission during human speech increase with voice loudness. Sci Rep 2019;9:2348. doi: 10.1038/s41598-01938808-z pmid: 30787335

4. Scheuch G. Breathing is enough: for the spread of influenza virus and SARS-CoV-2 by breathing only. J Aerosol Med Pulm Drug Deliv 2020;33:230-4. doi: 10.1089/jamp.2020. 1616 pmid: 32552296

5. Stadnytskyi V, Bax CE, Bax A, Anfinrud P. The airborne lifetime of small speech droplets and their potential importance in SARS-CoV-2 transmission. Proc Natl AcadSci U S A 2020;117:11875-7. doi: 10.1073/pnas.2006874117 pmid: 32404416

6. Wu Z, McGoogan JM. Characteristics of and important lessons from the coronavirus disease 2019 (COVID-19) outbreak in China: summary of a report of 72314 cases from the Chinese Center for Disease Control and Prevention. JAMA 2020.

7. Wan Y, Shang J, Graham R, et al. Receptor recognition by novel coronavirus from Wuhan: An analysis based on decade-long structural studies of SARS. J Virol 2020; 94: e00127-20.

8. Hoffmann M, Kleine-Weber H, Schroeder $\mathrm{S}$, et al. SARS-CoV-2 cell entry depends on ACE2 and TMPRSS2 and is blocked by a clinically proven protease inhibitor. Cell 2020.

9. Goyal P, Choi JJ, Pinheiro LC, et al. Clinical characteristics of COVID-19 in New York city. N Engl J Med 2020;382: 2372-4.

10. Guan WJ, Ni ZY, Hu Y, et al. Clinical characteristics of coronavirus disease 2019 in China. N Engl J Med 2020;382:1708-20.

11. Steam inhalation therapy found to inactivate SARS-CoV-2 virions [Internet]. Newsmedical.net. 2020 [cited 2021 Apr 24]. Available from: https://www.newsmedical.net/news/20201130/Steaminhalation-therapy-found-to-inactivateSARS-CoV-2-virions.aspx. 